\title{
Use of railways for urban passenger transport
}

\author{
B. Abramović, M. Petrović \& J. Blašković Zavada \\ Faculty of Transport and Traffic Sciences, University of Zagreb, Croatia
}

\begin{abstract}
For many years the whole world has had problems with the issue of traffic congestion that results from the usage of road traffic, especially the traffic of passenger cars. The average occupancy of passenger cars amounts to 1.4 persons per vehicle, thus making this selection of the transport means the least economical regarding fuel consumption, occupancy of traffic areas and negative impact on the environment. The solution to the problem lies in a different traffic policy that will stimulate the usage of public urban passenger transit.

Apart from bus and tram transport the public transit in the City of Zagreb also uses rail transport. The railway line that passes through the City of Zagreb is located on the route of the Pan-European corridor X and the $\mathrm{b}$ branch of Corridor $\mathrm{V}$. For the needs of this paper, the section of the line in relation to Zagreb Main Railway Station-Sesvete is of interest, because the Scientific-Academic campus Borongaj (ZUK Borongaj) is located south of the mentioned section. In October 2007 three faculties moved to ZUK Borongaj and the moving of five more faculties as well as the construction of a student hostel are expected there in the near future. This leads to the conclusion that there will be an increase in the number of people who will gravitate to the area of ZUK Borongaj and therefore the new gravitation area will have to be studied.

Apart from the technical-passenger station, which is next to ZUK Borongaj, a new stop for urban-suburban passenger transport is planned. It is therefore necessary to make certain modifications in the mentioned section of the railway line regarding the location and the number of stops.

Since the move to ZUK Borongaj has been planned in three phases, each of these requires an estimate of the number of students, teachers and other staff members who will arrive at the Campus. It is also necessary to use surveys to make a distribution to certain transport modes. Furthermore, each phase will require an analysis of the usage of the rail transport means capacity and based on this a proposal for a new organization of train operation.
\end{abstract}

Keywords: urban transport, railway transport, catchment area, distribution. 


\section{Introduction}

For many years the actual problem has been road congestion caused by passenger cars. As known the average occupation of passenger cars is 1.4 persons per vehicle, which renders this type of transport uneconomical in the sense of fuel consumption, occupation of traffic areas and its impact on the environment. The alternative is to use public urban transit (trams and buses) and the railway.

In the Republic of Croatia, or more precisely in the area of the City of Zagreb, public urban transit still fails to be competitive to individual traffic, and in order to achieve this the following properties need to be fulfilled: speed, safety, punctuality, reliability and economy. Taking Zagreb as an example, the drawback of public urban transit is, among other things, the insufficient connection to the peripheral parts of the city with the city centre. This problem is resolved by using the railway traffic subsystem in the urban-suburban area, since it is precisely the railway that plays a big role in passenger transport during morning and afternoon commuting. In order to make the railway traffic even more competitive in relation to individual traffic it is necessary to meet certain pre-conditions:

- $\quad$ provide sufficient number of trains,

- $\quad$ organize and equip the stops taking into account the connections with other traffic modes (road-railway P\&R, PUT-railways),

- $\quad$ provide train headways from 7 to 10 minutes,

- $\quad$ modernize protection at all level crossings (LCs), provide grade separation of LCs on railway lines with high intensity of road traffic,

- $\quad$ in the urban area construction of double-track lines, in order to segregate urban-suburban from long-haul traffic.

\section{Traffic demand of the urban area of Borongaj}

There are two Pan-European Corridors passing through the City of Zagreb, Corridor $\mathrm{X}$ and branch $\mathrm{b}$ of Corridor $\mathrm{V}$. For this paper the section of the railway line Zagreb Main Railway Station-Sesvete is interesting since to the south of the railway line there is the area of the Scientific-Academic campus, which already accommodates three faculties; five more faculties are to be moved there, and the plan includes also the construction of a student hostel. Regarding the expected growth in railway traffic users, the paper requires an analysis of the suburban traffic at the mentioned line with special emphasis on the catchment area of the Borongaj railway station with the intention of establishing a new stop.

Borongaj district spreads between Branimirova Street to the North, Donje Svetice Street to the West, Borongajska Road to the South and the Trnava settlement to the East. The railway line Zagreb Main Railway Station-Sesvete passes along the northern side of Borongaj and the Borongaj railway station is situated on it. According to the current organization of train traffic, the Borongaj railway station is not planned for passenger handling. The stops Maksimir and Trnava are planned for this purpose. 
Studies have shown that the railway transport users are ready to walk $700 \mathrm{~m}$ to the nearest stop and those who arrive from greater distances use cars or bicycles so that this requires provision of parking places. For the needs of this paper, the catchment area will be studied in order to form a new stop at the Borongaj station. Within the radius of $700 \mathrm{~m}$ from the railway station to the South, there is the area of the Scientific-education campus and the industrial zone, and to the North there is the department store Kaufland, DTR - underwear factory, food industry Mlinar, tram depot and bus depot, service centres, tennis centre and a residential area.

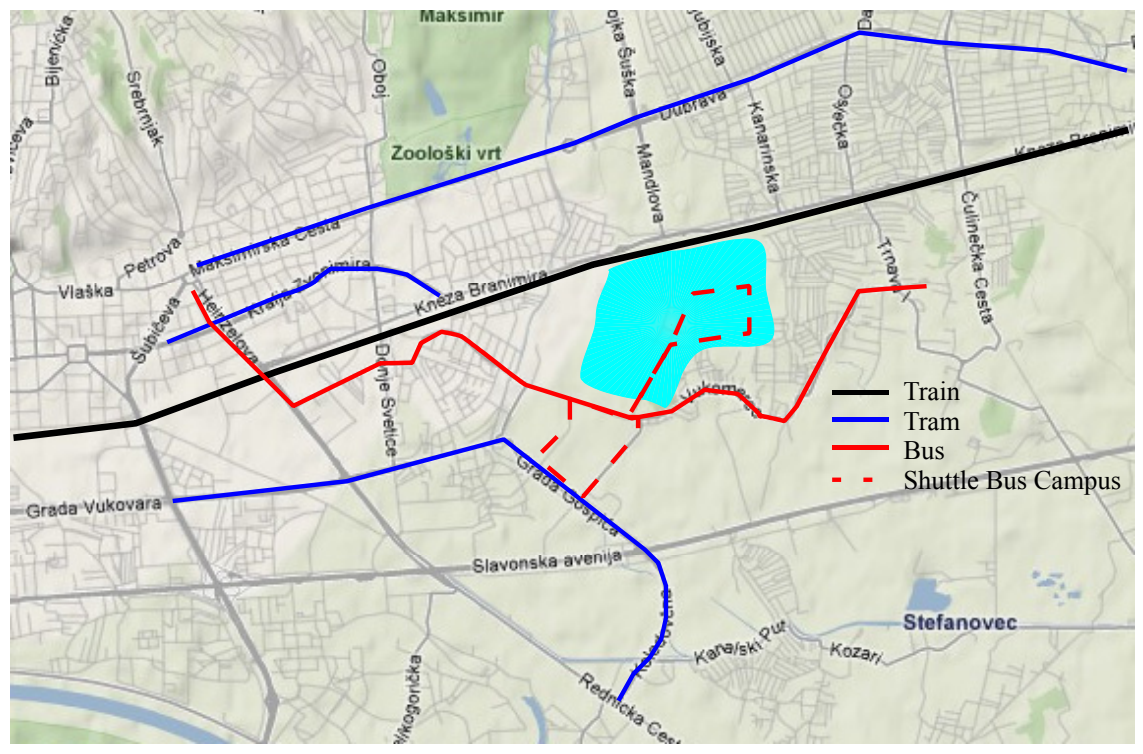

Figure 1: Borongaj Campus and the neighbourhood.

\section{Analysis of the current condition on the Zagreb main railway station-Sesvete railway line}

On the section of the railway line from Zagreb Main Railway Station to the Borongaj station there are two one-track lines equipped with $\mathrm{AB}$ in both directions, whereas from Borongaj to Sesvete there is a double-track line also equipped with $\mathrm{AB}$. The following traffic places are planned for passenger handling:

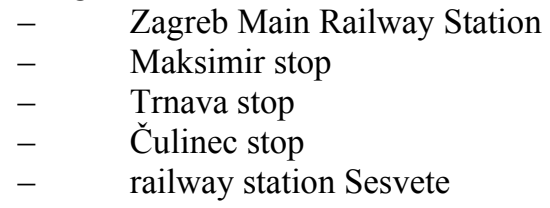

Electric railcars of the 6111 series operate on the respective railway line for the needs of urban and suburban traffic with the following performances: 
- $\quad$ year of production 1976-79

- $\quad$ electric supply system $25 \mathrm{kV}$ and $50 \mathrm{~Hz}$

- $\quad$ maximum speed $120 \mathrm{~km} / \mathrm{h}$

- $\quad$ length of composition $72.4 \mathrm{~m}$

- $\quad$ total number of places is 466 out of which 236 places are seats and the remaining 230 are standing places.

Regarding the age of the trains, modernization was needed and modernization resulted in the increase of the total number of places to 543 out of which 137 seats and 406 standing places.

For the needs of the analysis of the current condition on the respective section of the railway line, it is necessary to analyze the train schedule between the Zagreb Main Railway Station and the Sesvete station as well as the headways between two subsequent trains. There are 73 trains operating daily on the relation from the Zagreb Main Railway Station with average headway of $15 \mathrm{~min}$. For the peak traffic for Campus, which means between 7:00 and 8:30, there is a total of 9 trains operating with headway of 13.5 minutes. In the afternoon peak period between $14: 00$ and $16: 30$ a total of 12 trains operate with average headway of 13.3 minutes. On the relation from Sesvete there is a total of 78 trains operating with average headway of 15 minutes. In the morning peak period there are 9 trains operating with average headway of 8.9 minutes and in the afternoon peak period there are 12 trains operating with average headway of 13.7 minutes.

\section{Proposal on new organization of suburban traffic}

With the construction of the Borongaj Campus the transport demand in this direction is expected to increase. Eight faculties, three scientific institutes are expected to move to the Campus and the construction of student hostels there is expected as well. The capacity of the student hostels should amount to 5,000 places. According to the data of the faculties that are to be moved, the Campus is expected to accommodate 15,000 students and 2,500 members of the teaching and other staff.

The survey carried out for the needs of this paper has resulted in the data on the distribution to transport modes used by the students and teaching and other staff employed at the Campus. The following has been taken into consideration in order to evaluate the distribution:

- $\quad$ establishment of the new railway station Borongaj,

- $\quad$ connection of the Campus by public urban transit (tram - bus),

- construction of cyclist paths.

This means that the arrival to Campus will be possible by rail, public urban transit (bus and tram), by bicycle, passenger cars and walking. Figure $\mathrm{X}$ shows graphical presentation of the distribution of movements for students according to transport modes and according to moving phases.

The following distribution of movements has been assumed for teachers and other staff employed at the Campus, presented in the Figure.

The moving is planned in the zero, first and second phase. 


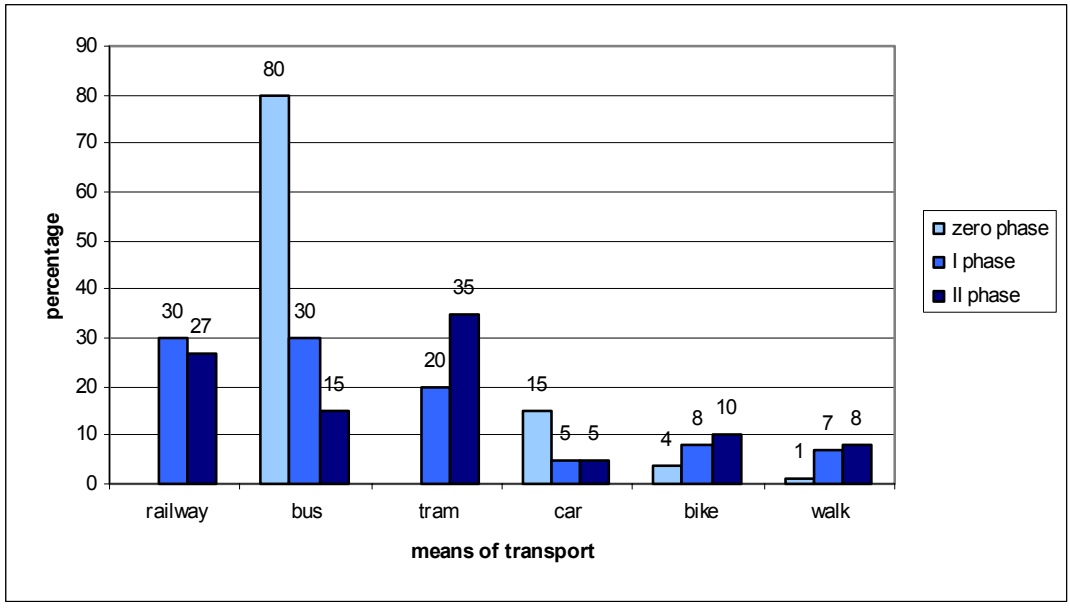

Figure 2: Distribution of modes for students.

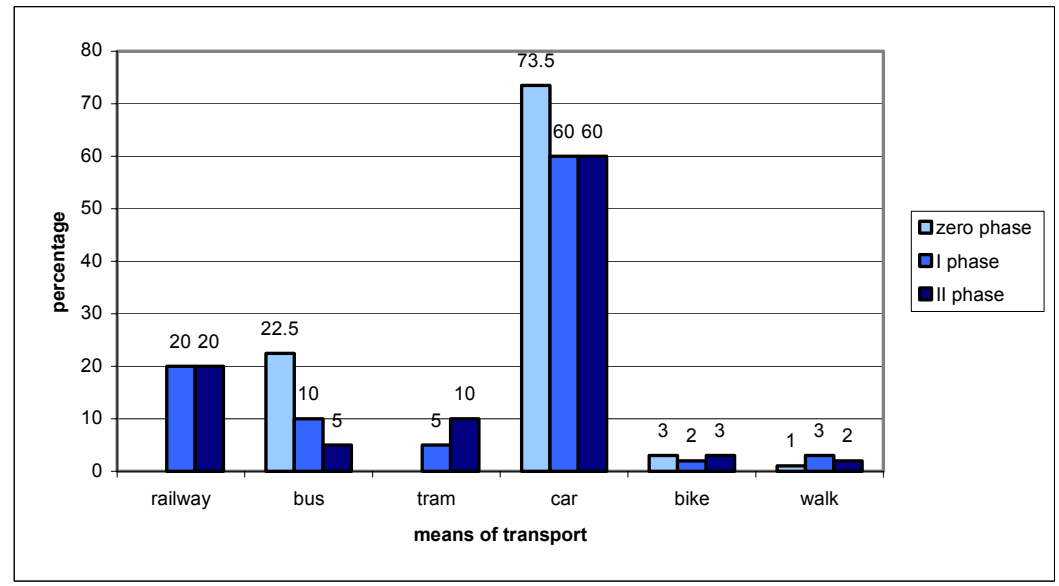

Figure 3: Distribution of modes for the teaching and other staff.

\subsection{Zero phase of the Borongaj Campus operation}

Zero phase of the operation represents current condition at the Borongaj Campus. Three faculties have moved to the Campus with 4,500 students and 500 members of the teaching and other staff. In this phase the Campus can be reached by public urban transit with one bus line ending / starting at the Campus, and the second passing by the Campus. Currently, railway station Borongaj located next to the Borongaj Campus has not been planned for passenger handling, and the rail transport users use the stops Maksimir and Trnava, changing from these stops to bus lines, that is, railway stops are at a 30 -minute walk distance. 


\subsection{First phase of the Borongaj Campus operation}

The first phase differs from the zero phase in that it plans the construction of the Borongaj stop next to the Campus area, and the distribution per transport modes is presented in Figure X.

The distribution of usage of modules could be that $70 \%$ students and $90 \%$ of teaching and other staff travels to Campus in the period from 7:00 to 8:30. Taking into consideration the mentioned distribution for the first phase the railway transport service would be used by 1350 students out of which 945 would be arriving between 7:00 and 8:30. Regarding the teaching and other staff it is considered that 100 would use railway as transport means, and 90 would be arriving within the mentioned period.

Since the Campus is located in the eastern part of the city, it is estimated that $80 \%$ of users would be arriving by trains from the direction of the Zagreb Main Railway Station, and only $20 \%$ from the direction of Dugo Selo and Sesvete. If the passengers are uniformly distributed to trains that operate in the respective period an increase in the number of passengers per train of 92 in the direction Zagreb Main Railway Station-Dugo Selo can be expected, whereas an increase of 23 passengers per train is expected in the opposite direction. Uniform distribution is rarely possible in practice, It is consequently assumed that $70 \%$ of the users will arrive to the Campus at 8:00 which eventually means an increase of 121 passengers per train in the direction Zagreb Main Railway StationSesvete and 30 passengers in the opposite direction.

The period between 14:00 and 16:30 is planned for the departure of the majority of students and staff, which means an increase of 112 passengers per train in the direction of Zagreb Main Railway Station and 28 passengers in the direction of Sesvete.

\subsubsection{First phase forecasts}

In the time period between 7:00 and 8:30 from the Zagreb Main Railway Station to Borongaj there will be an increase in the number of passengers by 828 so that the usage level of train capacity will be $22 \%$ and new lines need not be introduced. From the direction of Sesvete to Borongaj, in the same period, there will be an increase by 207 passengers, which means the usage level of capacity of $61 \%$ so that again no new trains need to be introduced.

Thus, this distribution of travelling of the Campus users is possible with the existing schedule, providing there is the possibility of train connection at the Zagreb Main Railway Station from the direction of Karlovac, Zaprešić and Sisak to urban-suburban trains in the direction of the Campus, and also at the Dugo Selo railway station connection with long-haul trains from Koprivnica, Osijek, Novska and Vinkovci in the direction of the Campus.

\subsection{Second phase of the Borongaj Campus operation}

The second phase plans the moving of the remaining five faculties, three scientific institutes and the construction of a student hostel which means that the total number of students at the Campus would be 15,000, and of the teaching and 
other staff about 2,500. Apart from the Borongaj stop, the General Urban Plan foresees the organization of cycling paths as well as better connection of the Campus with public urban transit (tram - bus).

It is assumed that in this phase $70 \%$ of students and $90 \%$ of the teaching and other staff will travel in the period from 7:00 to 8:30. According to the previous travel distribution, the number of students that would use railway transport amounts to 2,700 out of which 1,890 would travel within the mentioned period. According to travel distribution 500 teaching and other stuff will use rail and 350 of them would use rail during the mentioned time period.

If the number of passengers is distributed uniformly to trains that operate in the mentioned period from the direction of the Zagreb Main Railway Station, an increase of 200 passengers per train is expected and 50 passengers per train in the opposite direction. If the passengers are not uniformly distributed, which is often the case in practice, an increase of 358 passengers per train from the direction of Zagreb Main Railway Station is expected and 90 passengers in the opposite direction.

\subsubsection{Second phase forecast}

In the second phase the total number of passengers distributed in two trains from the direction of the Zagreb Main Railway Station would amount to 728 passengers. Thus increased number of passengers could be transported provided the current operating compositions were doubled. It is assumed that by then all the operating compositions used at the mentioned relations will be modernized so that their capacity would amount to 1,086 places, and the usage level in that case would be about $67 \%$. Assuming uniform distribution to all trains that operate in the period between 7:00 and 8:30 the number of passengers per train will increase by 200 , which means that new trains need not be introduced.

From the direction of Dugo Selo and Sesvete the usage level would be about $78 \%$ and if 448 passengers who travel to the Campus are added to these trains, one can see the need to introduce new trains with double compositions.

\subsection{Dimensioning of the new Borongaj stop}

Since the Campus is going to increase to the volume of 15,000 students and 2,500 members of the teaching and other staff, this will result in the need to construct a new stop on the Zagreb Main Railway Station-Sesvete railway line.

The first step is the site selection for the stop. The stop has to be located so as to provide smooth operation of the rail traffic on the Zagreb Main Railway Station-Sesvete line and the newly generated pedestrian traffic in the NorthSouth direction (Branimirova Street-Campus). Another thing to bear in mind is the criterion of the pedestrian walking radius from the stop to the Campus. It is, namely, so that the pedestrian decides to use a transport module if it is at less than 15 minutes walking distance. In case of a longer walk, the pedestrian will opt for a traffic module that requires less walking.

The new Borongaj stop needs to be located along the central part of the Campus in order to minimize the walking distance from the stop to the destination thus meeting the criterion of pedestrian walking radius. In selecting 
the location of the new stop it is necessary to provide the possibility of a construction at two levels with the area of the Borongaj Campus and with the areas north of the Branimirova Street. According to the mentioned criteria, the most favourable location for the stop is in close vicinity of the Borongaj railway station terminal.

This location of the stop would be at a distance of $1,229 \mathrm{~m}$ from the existing Maksimir stop and $826 \mathrm{~m}$ from the Trnava stop.

Since in the first phase the stop will be used by 1,450 students, teaching and other staff, in the second phase 4,550 students, teaching and other staff, the stop has to be adequately dimensioned and equipped. The platform has to be 6 meters wide, 175 meters long, and the platform height should be 0,55 meters. The platform should be fitted with guidelines for the poor-sighted and the blind. Two staircases are required and a lift for the disabled persons. The platform will be connected to its surrounding by an overpass. The overpass will be completely closed by transparent walls. The overpass will start at Mandlova Street, pass the Branimirova Street then the passenger technical railway station Borongaj and will end at the Campus. The entries, i.e. exits will be fitted with directional signs and displays showing train arrivals and departures. The overpass will be minimally 6 meters wide. Architecturally, the overpass should be of a challenging design with emphasis on the connecting function of the railways and the Campus area.

The stop equipment includes: ticket selling machine, information panel, train arrival and departure displays, benches, press kiosk, or food and drink machines.

\section{Conclusion}

The problems of morning and afternoon congestion on the roads caused by passenger cars have been present already for a number of years. The attempts to resolve them mainly include motivating the passengers to use public urban transport through various measures of the traffic policy. The problem is present also in the area of the City of Zagreb and one segment has been studied in this paper.

At the city district Borongaj the decision was made to re-allocate the premises of the former barracks into a Scientific-academic campus Borongaj. The area is to accommodate eight faculties, three scientific institutes and a student hostel. Recalculated into the number of people who would daily visit the Campus, this means that 15,000 students and 2,500 members of teaching and other staff will be staying at the Campus. The move to the Campus is planned in three phases: zero phase, first phase and second phase.

During the zero phase, the Campus accommodates three faculties with 4,500 students and 500 members of the teaching staff. The Campus is very poorly connected by public urban transport with the rest of the city, since there are only two bus lines out of which one starts/ends tat the Campus, and the other passes by. The nearest stops of railway traffic are located at 30-minute walking distance.

The construction of the Borongaj stop is planned in the first phase. It will be located in the close vicinity of the Campus and the same number of people are 
expected as in the zero phase. Regarding the vicinity of the railway stop an increase in the traffic demand for this transport mode is expected. The paper analyzes the existing schedule of trains that operate on the respective line and the usage capacity of the trains has been analyzed. Based on the survey a distribution of passengers per transport modes has been obtained and these data were of great importance during the calculation of the usage of train capacities. It was concluded that during this phase it is not necessary to introduce additional lines during morning and afternoon peak hours.

The second phase plans the moving of the remaining five faculties, three institutes and a construction of a student hostel, which will represent a substantial increase in the number of people that will gravitate to the Campus. Based on the distribution on transport modes the usage of capacities of transport means of railway traffic has been re-analyzed. The analysis led to the conclusion that double compositions will have to be introduced.

The paper also describes the criteria for the selection of the location of the new Borongaj stop and based on them the positioning in the close vicinity of the railway terminal building of the existing Borongaj railway station has been proposed. Regarding the expected volume of passengers the dimensioning of the stop had to be done and the accompanying facilities proposed.

\section{References}

[1] Bogović, B.: "Prijevozi u željezničkom prometu", Fakultet prometnih znanosti, Zagreb, 2006

[2] Badanjak D., Bogović, B., Jenić, V.: "Organizacija željezničkog prometa", Fakultet prometnih znanosti, Zagreb, 2006

[3] White paper "European transport policy for 2010: time to decide", European Commission, Brussels, 2001

[4] Statistical Yearbook for 2007, 2006, 2005, 2004, 2003; CROSTAT - Central Bureau of Statistics - Republic of Croatia, Zagreb

[5] General Urbanistic Plan of City of Zagreb, 2008

[6] Abramović, B.; Jenić, V.; Bogović, B., Technology of suburban railway traffic. ICTS 2006 Transportation and globalization. Marina Zanne, Daša Fabjan, Peter Jenček, Portorož: Fakultet za pomorstvo in promet, 2006

[7] Barić, D.; Abramović, B.; Mlinarić, T.J., Methodological approach to selection of traffic branches in a suburban area of large cities. ICTS 2004 Transportation logistics in science and practice. Daša Fabjan, Nova Gorica: Fakulteta za pomorstvo in promet Portorož, 2004. 